\title{
Specialist to non-specialist teleconsultations in chronic respiratory disease management: A systematic review
}

\author{
Rutuja Patil ${ }^{1,2}$, Rahul \\ Shrivastava ${ }^{3}$, Sanjay Juvekar ${ }^{1,4}$, \\ Brian McKinstry², Karen \\ Fairhurst ${ }^{2}$; for the RESPIRE \\ collaboration
${ }^{1}$ Vadu Rural Health Program, KEM Hospital Research Centre, Pune, India ${ }^{2}$ NIHR Global Health Research Unit on Respiratory Health (RESPIRE), Usher Institute, University of Edinburgh, Edinburgh, UK
${ }^{3}$ KEM Hospital Research Centre, Pune, India
${ }^{4}$ Savitribai Phule Pune University, Pune, India

\begin{abstract}
Background Chronic respiratory diseases (CRD), are common public health problems with high prevalence, disability and mortality rates worldwide. Further uneven distribution of the health workforce is a major barrier to the effective diagnosis and treatment of CRDs. Teleconsultation between a specialist and non-specialist could possibly bridge the gap in access to health care and decrease CRD burden in remote areas. This review investigates the evidence for the effective use of specialist to non-specialist teleconsultation in the management of CRDs in remote areas and identifies instances of good practice and knowledge gaps.
\end{abstract}

Methods We searched for articles till November 2020, which focused on specialist to non-specialist teleconsultations for CRD diagnosis or management. Two independent reviewers conducted the title and abstract screening and extracted data from the selected papers and the quality was assessed by Joanna Briggs Institute's (JBI) tool. A descriptive and narrative approach was used due to the heterogeneous nature of the selected studies.

Results We found 1715, articles that met the initial search criteria, but after excluding duplicates and non-eligible articles, we included 10 research articles of moderate quality. These articles were from nine different studies, all of which, except one, were conducted in high-income countries. The studies reported results in terms of impact on the patients, and the health care providers including primary care physicians (PCP) and specialists. The teleconsulting systems used in all the selected papers primarily used audio modes in addition to other modes like the audio-video medium. The included studies reported primarily non-clinical outcomes including effectiveness, feasibility, acceptability and usability of the teleconsultation systems and only three described the clinical outcomes. The teleconsultation was predominantly conducted in the PCPs office with the specialist located remotely.

Conclusions We found relatively few, papers which explored specialist to non-specialist teleconsultation in management of CRDs, and no controlled trials. Two of the included papers described systems, which were used for other diseases in addition to the CRD. The available literature although not generalisable, encourages the use of specialist to non-specialist teleconsultation for diagnosis and management of CRDs.

The distribution of the health workforce across the globe is uneven and is often disproportionately lower in low and middle-income countries (LMICs) which are the areas often with the highest disease burden [1]. The World Health Organization (WHO)- Global Health Observatory reports that over $40 \%$ of member countries of 
WHO, all LMICs, have less than one physician per 1000 population [1]. The African Region suffers more than $24 \%$ of the global burden of all diseases but has access to only $3 \%$ of health workers and less than $1 \%$ of the world's financial resources [1]. The unbalanced distribution of health care personnel by specialities adds to these disparities [2]. In India, while $69 \%$ of Indian population resides in rural areas and they are served by $22 \%$ of all health care providers compared with the $31 \%$ urban citizens who have access to $78 \%$ of trained health care professionals [3,4]. Poor access to transport and inadequate transport infrastructure in rural areas further aggravates the scarcity of health care workforce leaving a large proportion of the rural population without easy access to trained health care providers.

Information technology can facilitate access to specialist services, by overcoming the distance barrier by enabling specialist doctors to provide remote consultations to patients and provide support to general physicians and specialised local health workers [5,6]. Additionally, remote consultations have also provided opportunities for continued access to health care when maintaining social distancing during the global COVID-19 pandemic [7]. Telehealth care is thus one possible means of addressing the challenges related to uneven access to health care in India and globally [8].

Telehealth care is variously referred to as telemedicine, telehealth, telecare, telemonitoring, tele(discipline), teleconsultation and also eHealth in assorted contexts including mobile application based care, self-management with the help of remote monitors, doctor-to-patient remote consultation and also doctor-to-doctor consultation [9]. COCIR, the European Trade Association, representing the medical imaging, radiotherapy, health ICT and electromedical industries suggests a simpler definition that: "Telemedicine includes all areas where medical or social data is being sent/exchanged between at least two remote locations, including both Caregiver-Patient/Citizen as well as Doctor to Doctor communication" [5]. This definition is most applicable where telemedicine seems to have widened its scope to a variety of health information exchange for managing health and well-being of the population. For this systematic review, we will refer to this as 'Teleconsultation'.

Chronic respiratory diseases (CRD) especially asthma \& Chronic Obstructive Pulmonary Disease (COPD) are common public health problems with high prevalence, disability and mortality rates worldwide [10-13]. Asthma is the $14^{\text {th }}$ most important disorder in the world in terms of the disease burden [14], and COPD is the third leading cause of death, worldwide [15]. Diagnosis of these chronic respiratory diseases is based on detailed patient history and clinical assessment, aided by specialised tests such as spirometry and peak expiratory flow readings. However, interpreting the results of such tests require specialised training [16]. Specialists are not always available in rural regions worldwide. A study conducted in the US reported that less than one-third of the rural population, but nearly $98 \%$ of the urban American population had access to a pulmonologist within a 10-mile radius [17]. The situation in low- and middle-income countries (LMICs) like India is comparatively worse. The Association of Chest Physicians of India lists 2413 chest physicians in a country of 1.3 billion people, more than $95 \%$ of these are registered at in large urban areas [18] as compared to American Thoracic Society comprising of more than 16000 registered members including physicians, researchers, advanced practice nurses, respiratory therapists which serves nearly 331 million population [19]. The rural areas in LMICs are primarily served by primary care physicians (PCP) or allied health staff including Auxiliary Nurse Midwives (ANMs) nurses or pharmacists for delivery of primary health care [20]. Lack of access to pulmonologists and other specialists required for the diagnosis and management of the CRDs may be one of the factors contributing to the misclassification or delayed diagnosis of CRDs and inappropriate disease management. Use of teleconsultation to remotely support the PCPs by engaging specialists could help in scaling up CRD diagnosis and treatment.

The objective of this systematic review was to explore the evidence for the effective use of specialist to non-specialist teleconsultation in the management of CRDs in adults in remote areas and to document best practices and challenges; and identify, knowledge gaps and provide recommendations for future research.

\section{METHODS}

\section{Search strategy}

A search strategy tool SPIDER (sample, the phenomenon of interest, design, evaluation, research type) [21] was used to design the search strategy. We consulted a librarian when creating the search strategy. The Search terms included variations of "Telehealth", "Telehealthcare", "eHealth", "Remote consultation", "Satellite consultation", "Remote diagnosis", "Remote management", "Teleconsultation", "Tele- opinion", "Tele- diagnosis", "Remote medical consultation", "Telemedicine", "Primary care", "Remote clinic", "Satellite clinic", "videoconfer- 
ence", variations of "Chronic Respiratory diseases", "Chronic obstructive pulmonary disease", "asthma", "Face to face consultation", "doctor to doctor consultation", "physician to physician", "referral", "consultation" (Appendix S1 in the Online Supplementary Document).

\section{Database}

We used Embase, Medline (through Ovid), PubMed, and CAB Global Health to run our search terms. RP handsearched citation lists to identify potentially relevant papers within retrieved papers and review articles.

\section{Search duration}

We searched for papers up to November 2019 and later the search was repeated in November 2020. We did not restrict the start date, although first publication in the search appeared in 1975.

\section{Inclusion and exclusion criteria}

We considered all types of research methodologies including interventions as well as observational studies. All types of teleconsultation between specialists and non-specialists for CRD diagnosis or management, including but not limited to email, videoconference, telephone etc. were included. We excluded articles, which were focused on home-based care, mobile health, doctor to patient consultations, molecular outcomes, pulmonary rehabilitation, telephone surveys, post-hospitalisation follow-ups, telemonitoring and tele-training. We also excluded reviews, systematic reviews and conference abstracts and the search was not restricted to any particular language.

\section{Data extraction and analysis}

The title and abstract screening followed by data extraction from the selected papers was independently conducted by two reviewers (RP and RS). The search results from all databases were imported into Mendeley (1.19.5) [22] and the duplicates were removed. The titles and abstracts were screened for all the papers. We selected studies mainly on two criteria. The first criteria is the disease condition, including at least one chronic respiratory illness, and the second criteria is consultation type, where a specialist provided consultation to non-specialists or a PCP, to either diagnose or treat the chronic respiratory disease.

Data extraction into Microsoft excel was developed based on the STROBE [23], NICE [24], CASP [25] and CONSORT [26] guidelines and included fields on the type and aim of the study, population description, disease condition, type of consultation, type of outcome and facility. The discrepancies were resolved by discussions between RP and RS. The narrative data was extracted using summary tables independently by two authors (RP and RS) which were later combined by one reviewer (RP) into one sheet and all authors reviewed this sheet regularly. Mendeley (1.19.5) [22] was used to manage references and MS-Excel (Microsoft Inc, Seattle, WA, USA) was used for data management. The quality assessment of the papers was carried out using the Joanna Briggs Institute's (JBI) tool for critical appraisal [27] by two reviewers (RP and RS). The discrepancies were resolved by discussion.

The study designs of the selected papers were heterogeneous thus a narrative approach to data synthesis was used rather than a meta-analysis.

\section{RESULTS}

The identified papers, the screening process, and the final number of studies included are detailed in the PRISMA flowchart (Figure 1). In summary, we found 1715 papers in the above-mentioned databases, of which 464 were duplicates, which were excluded, leaving 1251 papers. We screened the abstracts of all these 1251 papers of which 77 were selected for full-text screening based on the inclusion criteria. We further selected only published papers hence we did not include 21 meeting abstracts/conference papers. We found 10 relevant papers which included all three parameters of (i) teleconsultation, (ii) Specialist to non-specialist consultation (iii) CRDs.

\section{Study population}

The study populations in the selected studies primarily included two groups namely the patients and the health care provider including PCPs and specialists. Some studies also conducted secondary data analysis thus indirectly including patients as study participants [28,29]. The demographic characteristics of the study population were not described in any of the papers. The available details including a description of the recruitment methods in the included studies are described in Table 1. 


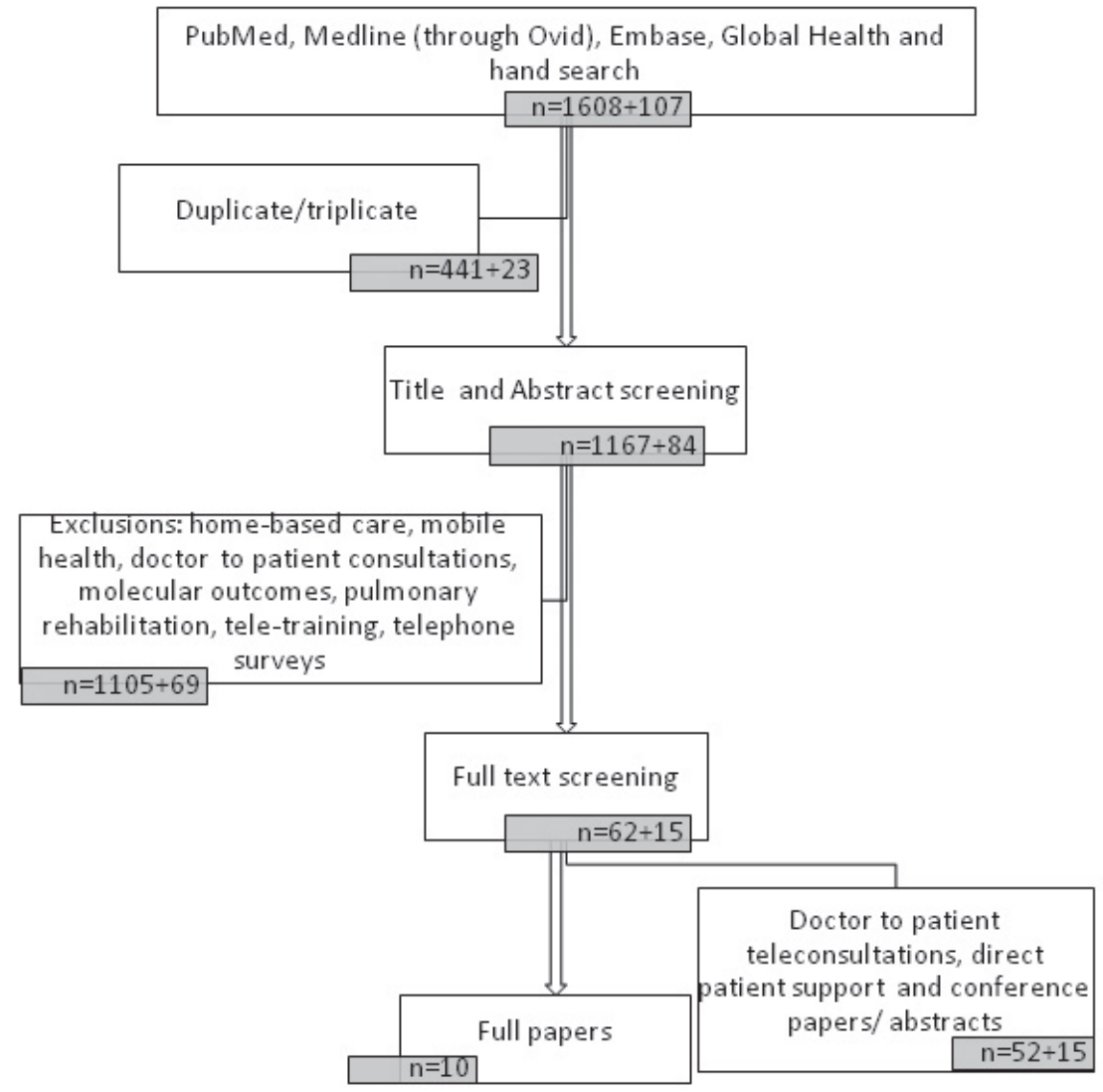

Figure 1. PRISMA-flow diagram for the selection of papers.

Table 1. Study population and selection criteria POPULATION DESCRIPTION

RECRUITMENT METHODS

SAMPLE SIZE

SAMPLING DETAILS/ TECHNIQUE

Koizumi et al [30]

Patients: The subjects were The two patients with chronic ob- ter structive pulmonary disease decided which included home monary Disease (COPD) receiving home ox- oxygen treatment. This treat- (COPD) patients. ygen treatment. Healthcare ment was assigned to the local Healthcare providproviders: Specialists at ter- hospital doctor through regular ers: tiary care hospital and prima- hospital visits who shared the ry care doctors from the local patient's information with the hospitals specialist

Raza et al [28] Patients: the patient at the Iron Pulmonary specialist catego- Patients: 314 pa- All patients presenting at the spoke site were Mountain clinic Healthcare rized the patient referral in tients in 684 clini- interviewed by Nurse for complaint medicaproviders: Pulmonary special- urgent and non-urgent. The cal encounters ist at the Milwaukee site and Non-urgent patients were elithe ancillary provider (nurse gible for teleconsultation. or respiratory technologist RT) at the Iron Mountain. tion and diagnostics if any. All patients who received pulmonology teleconsultation during the study period of seven years. Only non-urgent patients were considered suitable for telemedicine. The program provides outpatient teleconsultations (pulmonary, rheumatology, endocrine, mental health, and infectious disease). However, the paper presents data on pulmonary teleconsultations from one spoke site located $354 \mathrm{kms}$ away from the hub.

Averame et al [31] Patients: requiring telespirom- PCPs from all regions of Ita- Patients: 9312 pa- Not mentioned for PCPs and pulmonology etry. Healthcare providers: ly who were willing to partic- tients. Healthcare units. The participants were enrolled by the Primary Care Physicians (PCP) ipate and perform the spirom- providers: 638 PCPs PCPs from his/her general practice in the fol$\mathrm{s}$ and pulmonary specialist. etry were involved. Fifty-one 51 pulmonologist. pulmonary units distributed throughout the country were asked to participate in the study. However the methods do not describe how the participants were approached lowing categories of subjects: (1) current or ex-smokers without respiratory symptoms; (2) subjects with respiratory symptoms (3) subjects with a pre-existing clinical diagnosis of bronchial asthma; and (4) subjects with a pre-existing clinical diagnosis of COPD. 
Table 1. Continued

REPORT TITLE

Bonavia et al [32]
POPULATION DESCRIPTION RECRUITMENT METHODS

Patients: requiring telespi- PCPs from all regions of Italy Patients: 17910 pa- PCPs who were willing to conduct telespiromrometry. Healthcare provid- who were willing to participate tients. Healthcare etry. Pulmonology units identified by a steerers: PCPs and pulmonary spe- were involved cialist.

\section{providers: 937 PCPs ing committee. Subjects on whom the PCP} trained by 51 pulm- conducts telespirometry. The paper mentions onologists. that the details are described in another publication describing this study [31] however, no more details are mentioned about the recruitment methods

\begin{tabular}{|c|c|c|c|c|}
\hline \multirow[t]{2}{*}{ Bernocchi et al [33] } & $\begin{array}{l}\text { Patients: Patients who were } \\
\text { screened for eligibility before } \\
\text { hospital discharge and who } \\
\text { consented. }\end{array}$ & \multirow{2}{*}{$\begin{array}{l}\text { Patients at the PCP clinic. Be- } \\
\text { fore discharge from the hospital } \\
\text { all patients were given instruc- } \\
\text { tion on their respective disease } \\
\text { conditions (CHF or COPD). } \\
\text { Patients were given pointers for } \\
\text { recognizing signs and symp- } \\
\text { toms of decompensation/wors- } \\
\text { ening. Patients with CHF were } \\
\text { provided with a portable l-lead } \\
\text { electrocardiogram (ECG) de- } \\
\text { vice (Card-Guard 2206). Pa- } \\
\text { tients with COPD received a } \\
\text { pulse oximeter (Vitalaire, Ita- } \\
\text { ly) device }\end{array}$} & \multirow{2}{*}{$\begin{array}{l}\text { Patients: } 4925 \text { pa- } \\
\text { tients } \\
\begin{array}{l}\text { Healthcare provid- } \\
\text { ers: }\end{array}\end{array}$} & Not mentioned \\
\hline & $\begin{array}{l}\text { Healthcare providers: PCPs } \\
\text { and pulmonary specialist }\end{array}$ & & & \\
\hline Thijssing et al [34] & $\begin{array}{l}\text { Patients: Patients who were } \\
\text { considered suitable for the } \\
\text { telepulmonology consulta- } \\
\text { tions by the PCP. Healthcare } \\
\text { providers: PCPs and pulmo- } \\
\text { nary specialist }\end{array}$ & $\begin{array}{l}\text { All PCPs registered in the Neth- } \\
\text { erlands and in possession of a } \\
\text { spirometer that could be linked } \\
\text { to a computer were eligible. } \\
\text { PCPs opted in to join the tele- } \\
\text { consultation system }\end{array}$ & $\begin{array}{l}\text { Patients: } 1958 \text { tele } \\
\text { pulmonology from } \\
1828 \text { patients. } \\
\text { Healthcare provid- } \\
\text { ers: } 158 \text { PCPs and } \\
32 \text { pulmonologists. }\end{array}$ & $\begin{array}{l}\text { All PCPs registered in the Netherlands and } \\
\text { in possession of a spirometer that could be } \\
\text { linked to a computer. Participating PCPs de- } \\
\text { cided on suitability of tele pulmonology con- } \\
\text { sultation. All telepulmonology conducted } \\
\text { during the study period were included. }\end{array}$ \\
\hline Metting et al [35] & $\begin{array}{l}\text { Patients: Patients suspected to } \\
\text { have obstructive airway dis- } \\
\text { ease (OAD) Healthcare pro- } \\
\text { viders: PCPs and pulmonary } \\
\text { specialist }\end{array}$ & $\begin{array}{l}\text { Patients are decided by PCPs. } \\
\text { All PCPs in study area. Pul- } \\
\text { monologist who has assessed } \\
\text { more than } 300 \text { patients were } \\
\text { approached for the service }\end{array}$ & $\begin{array}{l}\text { Patients: } 11401 \text { pa- } \\
\text { tients Healthcare } \\
\text { providers: } 360 \text { PCPs } \\
\text { and } 10 \text { pulmonolo- } \\
\text { gists }\end{array}$ & Not mentioned. \\
\hline Fadaizadeh et al [36] & $\begin{array}{l}\text { Patients: Thoracic surgery pa- } \\
\text { tients who consented for tele- } \\
\text { consultation Healthcare pro- } \\
\text { viders: Physicians and nurses } \\
\text { at the hospital and Consulting } \\
\text { physician at remote location }\end{array}$ & $\begin{array}{l}\text { Patients selected for telecon- } \\
\text { sultation were mostly compli- } \\
\text { cated thoracic surgery cases } \\
\text { with multiple organ failure for } \\
\text { whom transportation was not } \\
\text { only infeasible, but also con- } \\
\text { traindicated. Physician locat- } \\
\text { ed in remote hospital and long } \\
\text { distance travel was required to } \\
\text { perform visit }\end{array}$ & $\begin{array}{l}\text { Patients: } 58 \mathrm{pa}- \\
\text { tients. Healthcare } \\
\text { providers: one con- } \\
\text { sulting physician }\end{array}$ & $\begin{array}{l}\text { All patients who consented to participate in } \\
\text { the study during the study period }\end{array}$ \\
\hline Weikert et al [37] & $\begin{array}{l}\text { Secondary data analysis no } \\
\text { study population }\end{array}$ & $\begin{array}{l}\text { Partner hospitals located in } \\
\text { Central Eastern Europe and } \\
\text { Asia were eligible to participate } \\
\text { in the cross-border teleradiol- } \\
\text { ogy program for a structured } \\
\text { expert consensus reading of } \\
\text { CTs with the clinical question } \\
\text { of IPF. Partner hospitals located } \\
\text { in Central Eastern Europe and } \\
\text { Asia were eligible to participate } \\
\text { in the cross-border teleradiolo- } \\
\text { gy program for a structured ex- } \\
\text { pert consensus reading of CTs } \\
\text { with the clinical question of IPF. }\end{array}$ & $\begin{array}{l}703 \text { HRCT scans } \\
\text { Data from } 239 \text { hos- } \\
\text { pitals located in } 46 \\
\text { cities in } 12 \text { coun- } \\
\text { tries }\end{array}$ & Not mentioned \\
\hline Wrenn et al [29] & $\begin{array}{l}\text { Patients: Patients attending the } \\
\text { service and who completed } \\
\text { the teleconsultation. Health- } \\
\text { care providers: PCP from eight } \\
\text { adult primary care sites at the } \\
\text { University of California, San } \\
\text { Francisco (UCSF), USA }\end{array}$ & $\begin{array}{l}\text { First } 200 \text { teleconsultations } \\
\text { during initial months of pro- } \\
\text { gram }\end{array}$ & $\begin{array}{l}\text { Patients: } 195 \mathrm{pa}- \\
\text { tients. Healthcare } \\
\text { providers: } 86 \text { PCP }\end{array}$ & Not mentioned \\
\hline
\end{tabular}




\section{Consultation type and facilities used}

We included studies where a specialist communicated with a non-specialist by teleconsultation for either diagnosis or management of the patient's condition. In one study, consultations were conducted in real-time [30], the others were stored and forwarded consultations, which meant the specialists were sent the patient details and reports by the non-specialists and the specialists provided their opinion to the non-specialists within a stipulated time frame.

The case studies conducted in Japan described a setup which comprised of equipment at three locations which included the home of two patients with chronic respiratory failure, the hospital of the attending PCP, and the hospital of the pulmonary specialist [30]. No other study reported home-based specialist to non-specialist teleconsultation.

The primary care centres or PCPs offices were used as the site of the teleconsultation in six studies which were reported in seven papers $[28,29,31-35]$ where the consulting specialist was located at a remote location. These studies could be categorised as the hub and spoke where multiple PCPs were provided with an opinion by specialists for either diagnosis or management of CRDs. In one study reported from the USA, the hub was located at Milwaukee Veteran Affairs Medical Centre (VAMC) pulmonary telemedicine clinic which was located away from the spoke centre at Iron Mountain VAMC [28]. Five other studies had similar approach where the teleconsultation was conducted at the PCPs office and the specialist provided an opinion for the diagnosis or management remotely $[29,31,32,34,35]$. The teleconsultation was conducted between specialists at local hospitals and specialists at a tertiary care hospital in two studies [36,37] (Table 2).

Table 2. Study characteristics

$\begin{array}{lclll}\text { REPORT TITLE } & \begin{array}{c}\text { YeAR OF } \\ \text { PUBLICATION }\end{array} & \text { COUNTRY IN WHICH THE } & \text { TYPE OF STUDY } & \text { DISEASE CONDITION } \\ \text { Koizumi et al [30] } & 2005 & \begin{array}{l}\text { Shinshu University } \\ \text { Hospital, Japan }\end{array} & \text { Case study } & \text { COPD } \\ & & & \end{array}$

Real-time communication between patient at home, attending primary care physicians (PCP) at hospital and pulmonary specialist at another hospital once a week.

\begin{tabular}{lllll}
\hline Raza et al [28] & 2009 & United States & $\begin{array}{l}\text { Retrospective anal- Pulmonary conditions } \\
\text { ysis for description } \\
\text { of a telepulmonol- } \\
\text { ogy clinic }\end{array}$ \\
\hline Averame et al [31] 2009 & Italy & $\begin{array}{l}\text { Observational Asthma and COPD } \\
\text { study }\end{array}$
\end{tabular}
Pulmonary Specialist to Nurse or respiratory technologist
Training to PCPs by pulmonologists followed by PCPs performing spirometry in their clinic which was checked for quality by the gen at the central office providing teleconsultation and further of- fered an interpretation of the results which was faxed to the PCPs' office.

\begin{tabular}{|c|c|c|c|c|}
\hline Bonavia et al [32] & 2009 & Italy & $\begin{array}{l}\text { Observational } \\
\text { study }\end{array}$ & $\begin{array}{l}\text { persistent respiratory symp- } \\
\text { toms, or a previous diagnosis } \\
\text { of asthma or COPD }\end{array}$ \\
\hline
\end{tabular}

raining to PCPs by pulmonologists followed by PCPs performing spirometry in their clinic which was checked for quality by the specialist at the central office and further offered an interpretation of the results which was faxed to the PCPs' office.

\begin{tabular}{|c|c|c|c|c|c|}
\hline Bernocchi et al [33] & 2012 & Italy & $\begin{array}{l}\text { Description and as- } \\
\text { sessment of an on- } \\
\text { going project }\end{array}$ & $\begin{array}{l}\text { Chronic Heart Failure, Skin, } \\
\text { Diabetes, Chronic Obstructive } \\
\text { Pulmonary Disease }\end{array}$ & $\begin{array}{l}\text { Second opinion for the PCPs in Cardiology, Der- } \\
\text { matology, diabetology and pulmonology }\end{array}$ \\
\hline Thijssing et al [34] & 2014 & Netherlands & Intervention study & COPD & Pulmonologists to PCPs \\
\hline Metting et al [35] & 2015 & Netherland & $\begin{array}{l}\text { A cross-sectional } \\
\text { baseline descrip- } \\
\text { tion and longitudi- } \\
\text { nal results }\end{array}$ & $\begin{array}{l}\text { Asthma, COPD and overlap } \\
\text { syndrome - obstructive airway } \\
\text { disease }\end{array}$ & $\begin{array}{l}\text { PCPs refer patients to service and tests are con- } \\
\text { ducted in laboratory. Pulmonologists inspect the } \\
\text { data through the internet and send the PCP diag- } \\
\text { nosis and management advice }\end{array}$ \\
\hline Wrenn et al [29] & 2017 & USA & $\begin{array}{l}\text { A retrospective de- } \\
\text { scriptive analysis }\end{array}$ & $\begin{array}{l}\text { Cardiology, Endocrinology, } \\
\text { Gastroenterology/hepatology, } \\
\text { Haematology, Infectious dis- } \\
\text { eases, Nephrology, Pulmonary } \\
\text { medicine, Rheumatology }\end{array}$ & $\begin{array}{l}\text { Specialist provided teleconsultation to patients via } \\
\text { the PCPs }\end{array}$ \\
\hline Fadaizadeh et al [36] & 2018 & Iran & $\begin{array}{l}\text { Cross-sectional In- } \\
\text { terventional }\end{array}$ & $\begin{array}{l}\text { Patients who have indergone } \\
\text { thoracic surgery with multiple } \\
\text { organ failure }\end{array}$ & Pulmonologists to PCPs \\
\hline Weikert et al [37] & 2019 & $\begin{array}{l}\text { Partner hospitals in } \\
\text { twelve Central East- } \\
\text { ern Europe and Asia } \\
\text { from the collabora- } \\
\text { tion framework with } \\
\text { Boehringer Ingelheim }\end{array}$ & $\begin{array}{l}\text { Description and } \\
\text { analysis of Inter- } \\
\text { vention }\end{array}$ & $\begin{array}{l}\text { presence of Usual Interstitial } \\
\text { Pneumonia (UIP)-pattern in } \\
\text { patients with suspected Idio- } \\
\text { pathic Pulmonary Fibrosis }\end{array}$ & $\begin{array}{l}\text { Radiologist and a pulmonologist reported the di- } \\
\text { agnosis of HRCTs to another pulmonologist or a } \\
\text { referring physician }\end{array}$ \\
\hline
\end{tabular}




\section{Details of the systems used for teleconsultations}

The specific teleconsultation systems used in all the selected papers varied; broadly they primarily used audio modes but some use a mixture of audio-video. Three papers from two studies focused on diagnosis using telespirometry.

Koizumi et al. shared clinical information, using a remote biological information transmission device which was installed at the patient's home. Equipment to measure arterial blood oxygen saturation and blood pressure was set up on the patient's finger along with three electrodes for Electrocardiogram. The remote consultation management device was set up at the attending PCPs hospital. Besides, another device for consultation management and monitoring was set up at Shinshu University Hospital, where the pulmonary specialist was located [30].

Another study described a hub-and-spoke model where the nurse or respiratory therapist (RT) at the spoke site recorded the clinical history and conducted a focused pulmonary physical examination. Medical consultations at the hub site were conducted via the live, two-way audio and video conferencing system. The physician at the hub site viewed chart notes and images of Electrocardiogram and radiographs and further prescribed diagnostics, medicines and suggested if the patient needed face to face consultations [28].

The Italian Alliance study published two papers in 2009 focusing on telespirometry for diagnosis of CRDs. One pulmonary specialist provided education and training on spirometry and diagnosis of obstructive airway diseases, to a group of PCPs in a six-hour education session. Each PCP was equipped with a simple, portable pneumotachograph (Spirotel, MIR, Roma, Italy) to measure the main indices derived from a maximal forced expiratory manoeuvre, the reports of which were transmitted to a central office. The operator at central office established a real-time communication and commented on the quality of the spirometry traces, invited the PCP to perform additional expiratory manoeuvres in the same subjects, and offered an interpretation of the results of the single patient. Then, the report was sent by fax to the PCPs office [31,32].

The descriptive paper on the TELEMACO project narrates that a service centre provided support to PCPs during daily in-office or home visits and for pulmonology consultations, PCPs contacted the service centre using a real-time telephone only and no special service was used [33].

An intervention study focused on telepulmonology consultations used a hypertext transfer protocol secured, web-based teleconsultation system for communication between PCP and pulmonary specialist. PCPs accessed a secured web-based teleconsultation system (KSYOS Telemedical Centre, Amstelveen, The Netherlands) where they completed the patient personal data, added up to four PDFs of the spirometry results and optionally added additional relevant clinical information. This information was sent to the local pulmonary specialist who had to answer within two working days [34].

Another study which focused on providing asthma and COPD services used an Electronic diagnostic support (EDS) system. After referral of a patient by the PCP to the asthma COPD services, a trained lung function technician conducted spirometry and along with the patient completed the patient information and clinical history in the EDS. This information was accessed by a Pulmonary specialist for assessment within five days which was then reported to the PCP who further decided on disease management [35].

A similar store and forward system was used by Fadaizadeh et al. for patients who have undergone thoracic surgery with multiple organ failure. The receiving PCP provided all necessary documents (the patient's history, tests, ECG, radiology documents) and transfer to the specialist via store and forward, and then discussed the case online via videoconference. Fibre optic communication; and web conference software was used for a simultaneous audio-visual connection. Tele-examination devices and equipment were provided including a camera for examining the ear, eye and also digital stethoscope for heart and lung examination. A communication network for specialised consultations was established among seven specialised hospitals [36].

The study which described the use of High-Resolution Computed Tomography (HRCT) scans for identifying Usual Interstitial Pneumonia (UIP)-pattern in patients with suspected Idiopathic Pulmonary Fibrosis with clinicians performing the Chest HRCT scans locally at the referring hospitals. The HRCT scans were sent for a centralised expert consensus reading by a radiologist and a pulmonary specialist. After registration, a pulmonary specialist in partner hospitals received a personalised upload link valid for a single patient who had consented and for short period. All data for the patient were uploaded to the central expert reading site. A radiologist and pulmonary specialist together generated report for the patients and the reports were sent back by encrypted email to the referring PCP in the local hospital [37].

A retrospectively described study used eConsult services, where the PCPs at the point of referral, had the option to submit an eConsult request, using a structured template, if they believed the specialist could address 
the clinical question without an in-person evaluation. Specific structured referral templates for the most common clinical problems referred to each speciality, which incorporated relevant laboratory data from the EHR, allowed PCPs to identify if relevant imaging data were available, and asked the PCP to provide a recent assessment and a specific clinical question [29].

\section{Study outcomes}

The included studies focused primarily on non-clinical outcomes including effectiveness, feasibility, acceptability and usability of the teleconsultation systems. Three of the 10 studies described the clinical outcomes more clearly $[28,35,37]$ one study which described observations of patients' assessment as clinical outcomes [30] did not provide sufficient details to assess their methods. The description of the study methods used to collect the data and respective study outcomes are listed in Table 3. We further describe the common conclusions from all the 10 selected papers.

\section{Effectiveness}

Two papers described the effectiveness of the existing system. Koizumi et al. describes that the system was effective for establishment of appropriate treatment, provided the cooperation between the pulmonary specialist and attending PCP was established and further suggests that a similar system could be considered useful and promising for further use [30]. Fadaizadeh et al. studied teleconsultation between physicians and nurses at the thoracic surgery hospital and consulting physicians, in thoracic surgery patients in intensive care unit and concluded that teleconsultation improved decision-making in thoracic surgery ICU patients through time saving and accelerating off-site consultations [36] (Table 4).

\section{Reliability}

The use of specialist to non-specialist teleconsultation was considered reliable in terms of technical feasibility $[28,29,33,35,37]$. However, concerns were raised in one study that the pulmonary specialist relied primarily on medical history, medical data from tests including radiology, and a limited physical exam performed by a trained nurse or respiratory therapist to arrive at clinical diagnosis [28].

\section{Improved patient access}

The systems utilised in multiple studies were reported as improving health care access to patients. Referred patients were able to receive medical subspecialty care closer to home, obviating the need for long-distance travel to receive an in-person medical consultation [28,33,35] (Table 3).

\section{Use of teleconsultation for diagnosis}

Three papers primarily focused on disease diagnosis [31,32,35]. The Italian Alliance study shows that telespirometry in the primary care setting could reliably demonstrate spirometric abnormalities and detect airflow limitation even in asymptomatic patients who are at risk of suffering from CRDs [31,32]. Another study also supported the finding that teleconsultation was feasible, effective and efficient in supporting PCPs to diagnose and manage asthma, COPD and overlap syndrome patients [35] (Table 3).

\section{Acceptability}

Specialist to non-specialist teleconsultation is highly dependent on the collaboration between health care providers and how acceptable they found the systems. Fadaizadeh et al. reported high physician satisfaction and acceptance of teleconsultation by the specialists [36]. Further, telespirometry was well accepted and could be easily performed by a large number of PCPs [31,32]. The rate of acceptable spirometric tests can be improved if the tests are performed under the supervision of trained technicians rather than by the PCPs $[28,33,35]$. One study showed that the service was perceived to stimulate cooperation between primary and secondary care, and deliver support to patients locally which is important in rural areas [35]. Telepulmonology, by improving the collaboration between PCP and pulmonary specialist, may prevent unnecessary face-to-face referrals thus saving time, and aiding in preventing under and misdiagnosis of COPD [34].

\section{Disease conditions}

COPD was addressed in two studies [30,34], both asthma and COPD in three studies [31,32,35], one study focused on general respiratory conditions [28] and two studies on multiple specialities, pulmonology being one of them $[29,33]$. Fadaizadeh et al. specifically investigated patients who had undergone thoracic surgery 


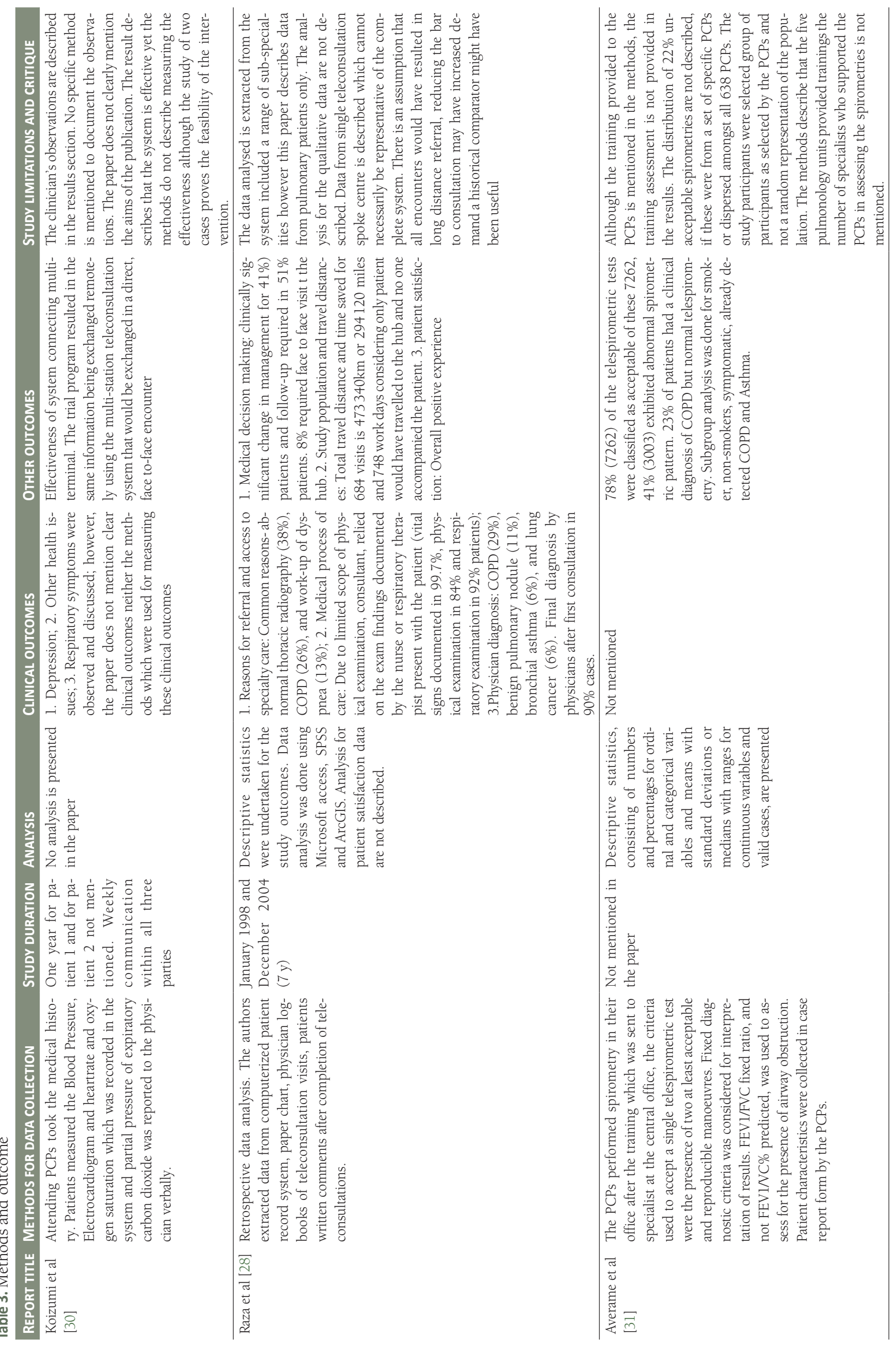

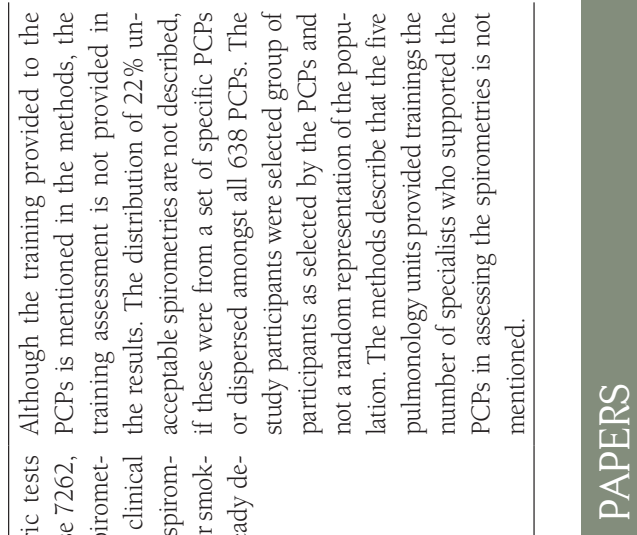

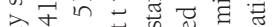

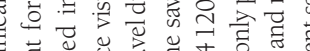

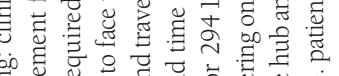

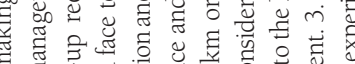

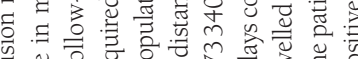

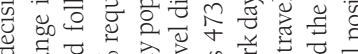

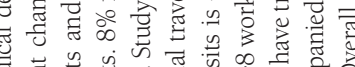

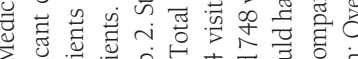

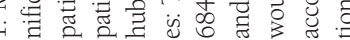

웡

b 군

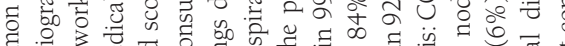
द्व

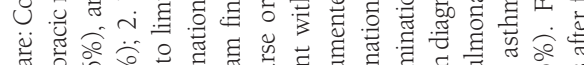

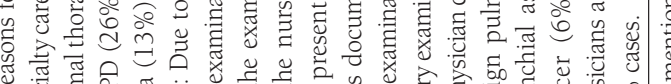

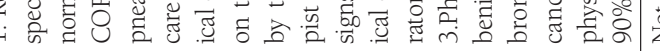

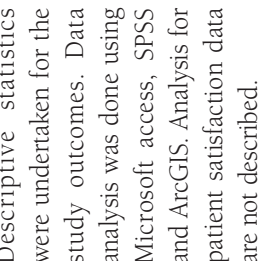




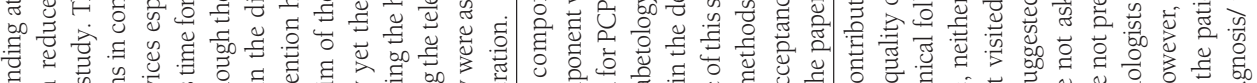

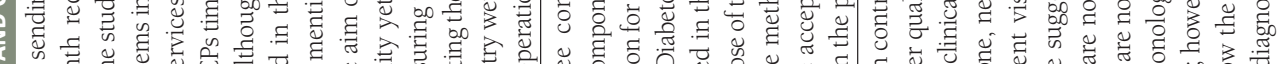

क

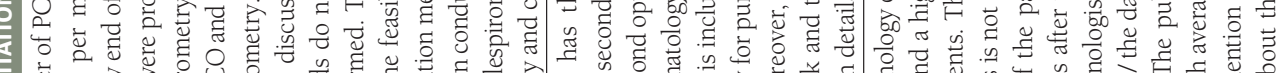

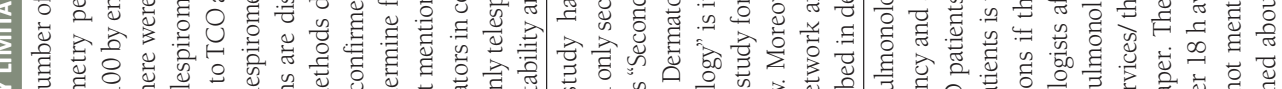

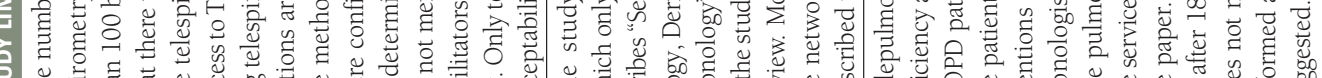

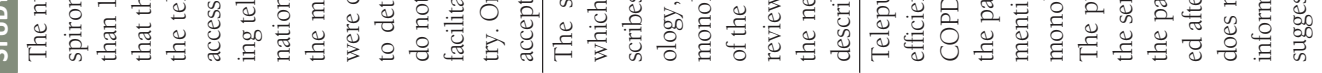

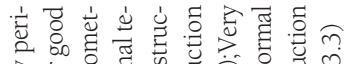

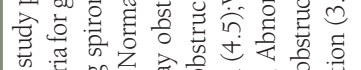

कo

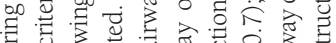

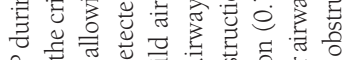

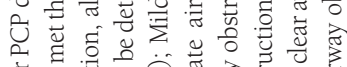

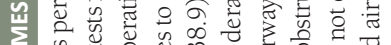

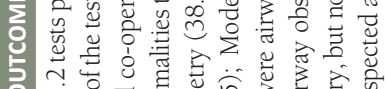

ते

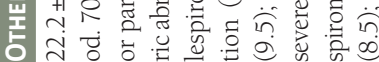

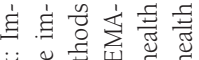

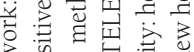

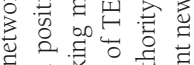

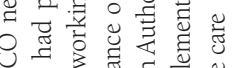

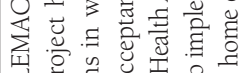

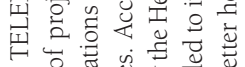

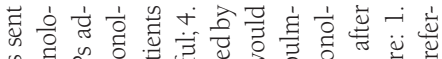

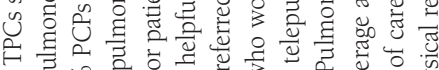

范。ํ.

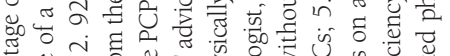

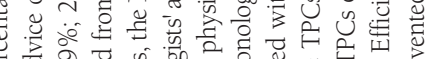

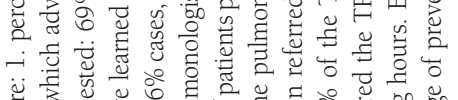

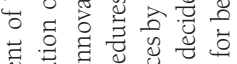

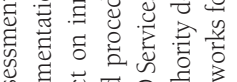

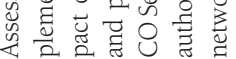

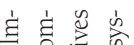

है, 矛艺

焉艺

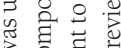

范芯

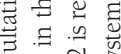

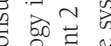

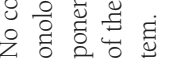

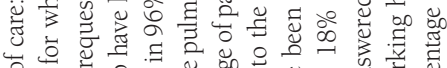

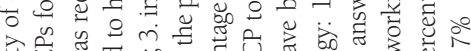

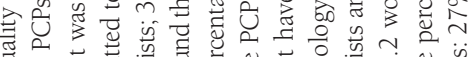

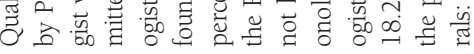

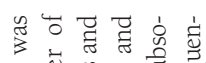

के

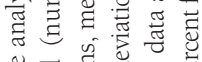

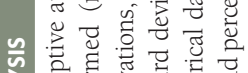

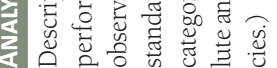

흔 $\overrightarrow{\tilde{\sigma}}$

ธิ

空

站范芯苍

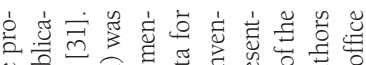

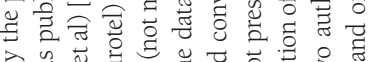

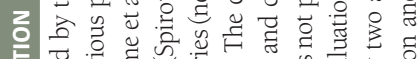

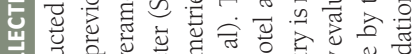

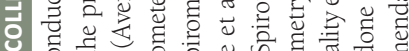

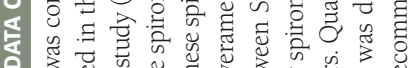

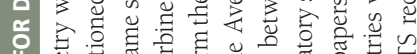

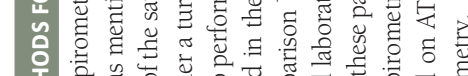

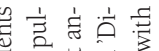

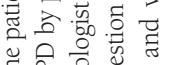

\%

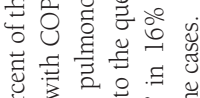

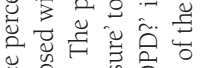

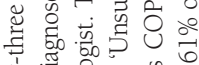

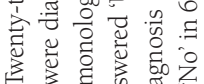

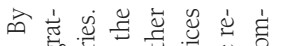

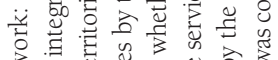

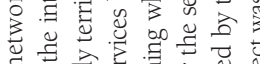

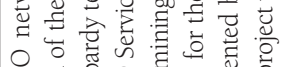

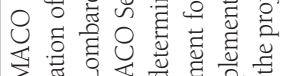

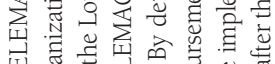

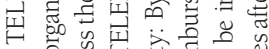

¿

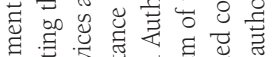

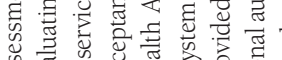

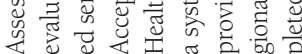

코

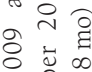

这

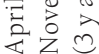

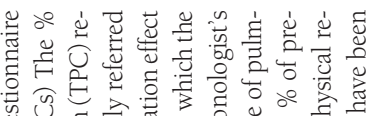

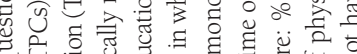

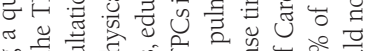

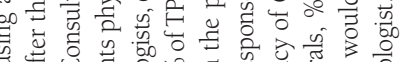

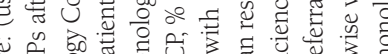

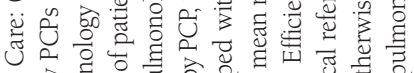

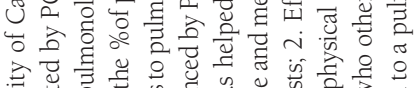

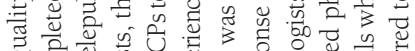

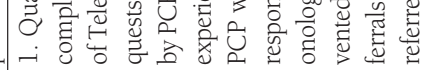

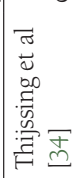




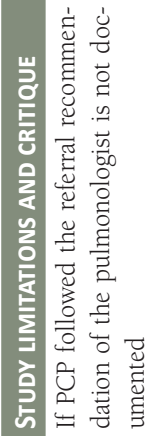

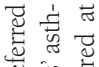

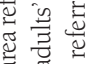 \\ 通 \\ 要 \\ \%

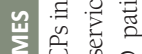 \\ 은

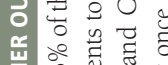

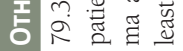

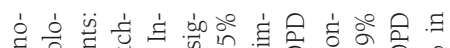

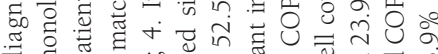

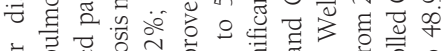

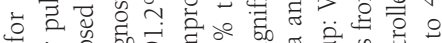

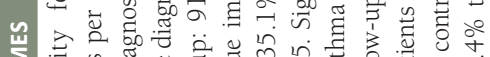

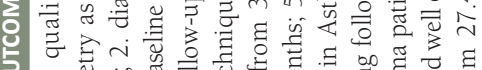

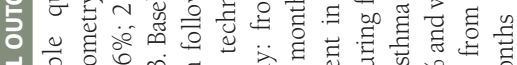

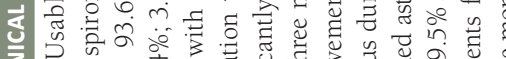

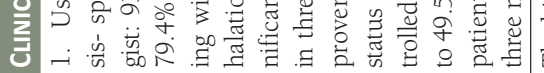

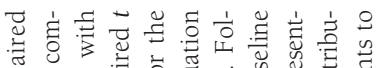

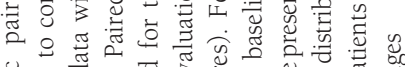

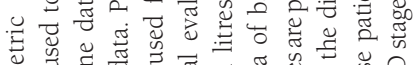

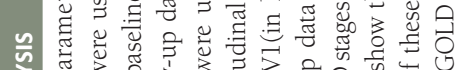

等

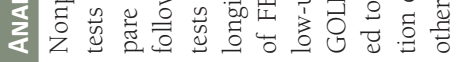

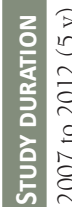

$\Xi$ \&

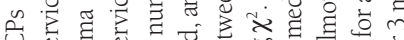

z

을

둤

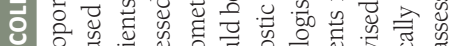

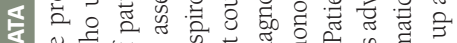

a

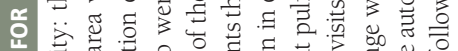

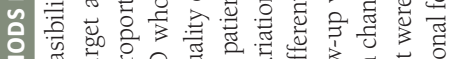

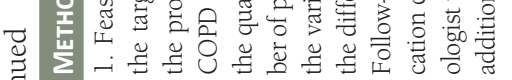

(3)

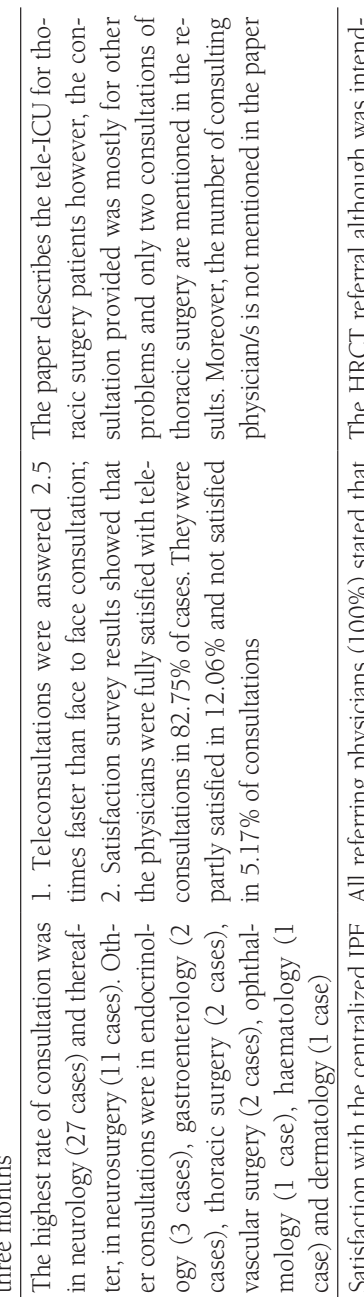

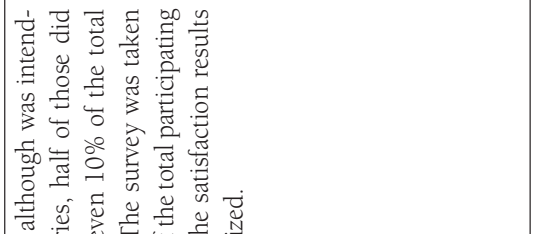

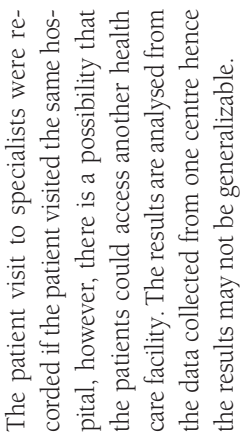

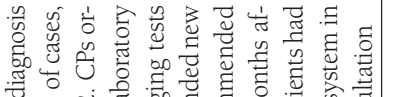

훈

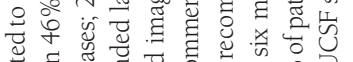

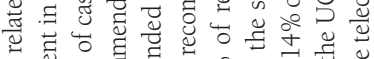

苛 。

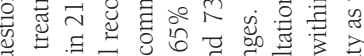

च ज्ञ

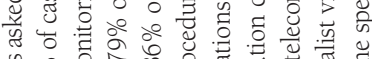

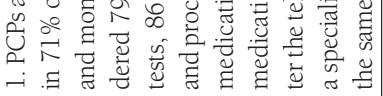

点苟

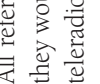

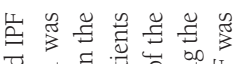

苟

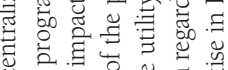

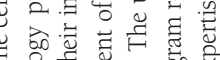

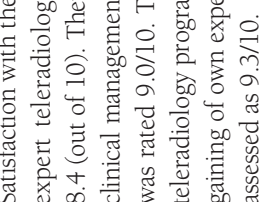

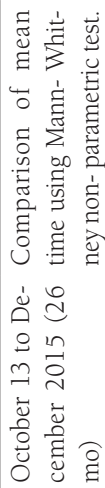

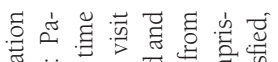

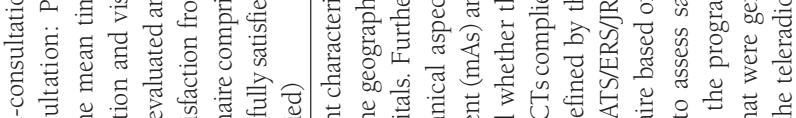

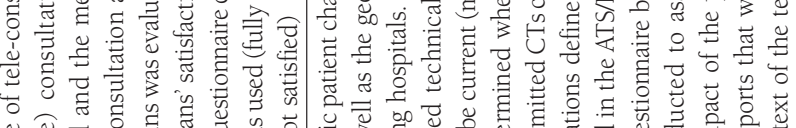

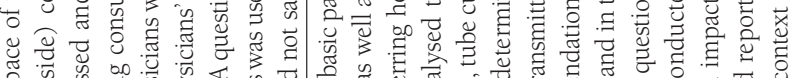

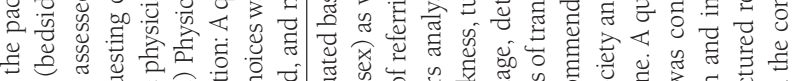

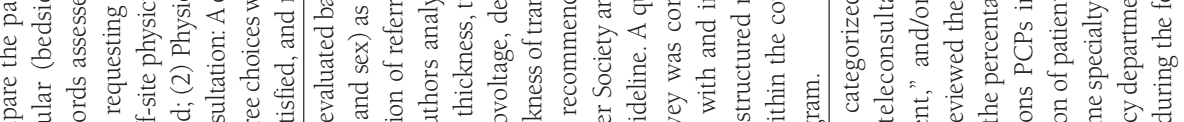

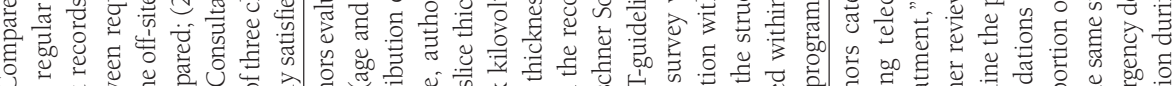

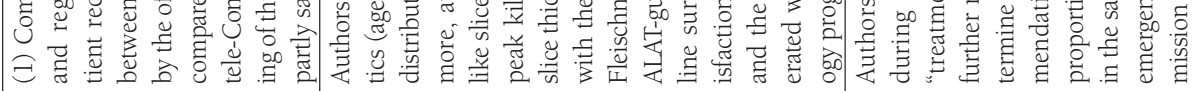

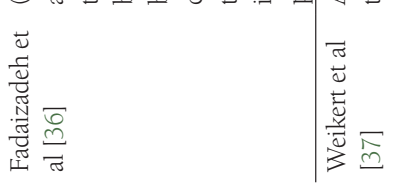


Table 4. Study aim and outcomes DESCRIPTION

AIM OF STUDY

TYPE OF OUTCOME MEASURE

FACILITY DESCRIPTION

Koizumi et al Two patients with chronic To create and test a multi-station telecon- The effectiveness of a system connecting Two patients with chronic respi[30] respiratory failure, attend- sultation support system, three remote multiple terminals for teleconsultation. ratory failure, the hospital of the ing PCP, and one pulmo- locations were connected: the homes of (Notes: although the methods to mea- attending PCP, and the hospital of nary specialist two patients with chronic respiratory sure the effectiveness is not described). the pulmonary specialist. failure, the hospital of the attending PCP The feasibility of use is established and a pulmonologist in another hospital

Raza et al [28] Six pulmonary specialist The goals of the study were (1) to eval- 1. Reasons for referrals and access to spe- Remote location (Spoke): Iron at the Milwaukee site and uate the use and effect of teleconsulta- ciality care; 2. Medical process of care 3. Mountain VAMC in Iron Mounthe patient and ancillary tion technology to provide consultative Physicians' diagnoses after teleconsulta- tain, MI and Provider (Hub): Milprovider (nurse or respi- outpatient care for a broad range of pul- tions 4. Medical decision making 5. Pa- waukee Veteran Affairs Medical ratory technologist - RT) monary conditions; and (2) To evaluate tient demographics 6. Patient Satisfaction. Centre (VAMC) pulmonary teleat the Iron Mountain. 314 the use of a teleconsultation program in 7. Number of visits and Travel distances consultation clinic patients

terms of (a) access to care (including re-

duction in both travel for patients and waiting time for appointments), (b) clinical decision making (medical interview and physical exam, medical work-up required, and outcome of teleconsultation), and (c) patient disposition (need for follow-up care and need for in- person evaluation)

Averame et al 638 PCP and pulmonary To report feasibility and usefulness of Diagnostic accuracy of PCPs interpreting PCP office and pulmonary units

[31] specialist for interpreting the telespirometry

Italian Alliance study. (Aim of the Alli- ing to ACCP GOLD and ATS/ERS Guideance study was (a) to improve the famil- lines iarity of PCPs with spirometry; and (b) to demonstrate the usefulness of a spirometric evaluation)

Bonavia et al large sample (937) of PCPs To report the results of an Italian study Feasibility of telespirometry in general PCP office and pulmonary units [32] from all regions of Italy and on the feasibility of telespirometry in practice Fifty-one pulmonary units general practice distributed throughout the country. 17910 subjects

Bernocchi et Patients, 176 PCPs two Combining management, clinical, and The aims of the project were 3-fold: (1) 1. Home-Based Tele management al [33] specialists technological tools to improve provision to implement and use continuity-of-care for Patients with Chronic Heart of health care in rural areas, from sec- services (2) to design a network in the ter- Failure or Chronic Obstructive ondary care community hospital settings ritory for sharing continuity-of-care pro- Pulmonary Disease 2. Second to home care grams for the management of chronic dis- opinion for PCPs at PCPs' Office eases (3) to allow the health authority to 3. Second opinion on digital imcollect data to establish sustainable pric- ages between PCPs office and speing at the regional health level for imple- cialist hospitals. menting TM

\begin{tabular}{|c|c|c|c|c|}
\hline $\begin{array}{l}\text { Thijssing et al } \\
\text { [34] }\end{array}$ & $\begin{array}{l}158 \text { PCPs and } 32 \text { pulmo- } \\
\text { nologists }\end{array}$ & $\begin{array}{l}\text { To assess the effect of telepulmonology } \\
\text { on quality and efficiency of care }\end{array}$ & $\begin{array}{l}\text { Effect of telepulmonology on quality and } \\
\text { efficiency of care }\end{array}$ & $\begin{array}{l}\text { PCPs office and pulmonary spe- } \\
\text { cialist's office }\end{array}$ \\
\hline $\begin{array}{l}\text { Metting et al } \\
\text { [35] }\end{array}$ & $\begin{array}{l}11401 \text { patients suspected } \\
\text { to have obstructive airway } \\
\text { disease (OAD) } 360 \text { PCPs } \\
\text { from north Netherland, } 10 \\
\text { pulmonologists }\end{array}$ & $\begin{array}{l}\text { To improve the management of asthma } \\
\text { and COPD patients in primary care using } \\
\text { an internet-based service }\end{array}$ & $\begin{array}{l}\text { Feasibility, effectiveness and efficiency in } \\
\text { supporting PCPs to diagnose and man- } \\
\text { age asthma, COPD and overlap syndrome } \\
\text { patients. }\end{array}$ & $\begin{array}{l}\text { PCP's office, Laboratory facility } \\
\text { for conducting spirometry and } \\
\text { pulmonary specialist's office. } \\
\text { Communication over internet }\end{array}$ \\
\hline $\begin{array}{l}\text { Fadaizadeh et } \\
\text { al [36] }\end{array}$ & $\begin{array}{l}\text { 1. } 58 \text { Thoracic surgery pa- } \\
\text { tients; 2. consulting phy- } \\
\text { sician located in a remote } \\
\text { hospital }\end{array}$ & $\begin{array}{l}\text { To assess the advantage of teleICU by } \\
\text { accelerating consultations and bringing } \\
\text { physicians' satisfaction from teleconsul- } \\
\text { tation outcomes }\end{array}$ & $\begin{array}{l}\text { 1. Comparison of the pace of teleconsul- } \\
\text { tation and regular(bedside) consultation } \\
\text { of ICU patients admitted during the year } \\
\text { before starting tele-ICU; 2. the physicians' } \\
\text { satisfaction from teleconsultation }\end{array}$ & $\begin{array}{l}\text { Tertiary pulmonology/ thoracic } \\
\text { surgery hospital (location of spe- } \\
\text { cialist is not mentioned) }\end{array}$ \\
\hline $\begin{array}{l}\text { Weikert et al } \\
\text { [37] }\end{array}$ & $\begin{array}{l}\text { Databased analysis no } \\
\text { study population. Data } \\
\text { from } 239 \text { hospitals located } \\
\text { in } 46 \text { cities in } 12 \text { countries }\end{array}$ & $\begin{array}{l}\text { To support referring centres to interpret } \\
\text { HRCT with respect to UIP in patient with } \\
\text { suspected Idiopathic Pulmonary Fibro- } \\
\text { sis (IPF) }\end{array}$ & $\begin{array}{l}\text { Feasibility of cross-border teleradiology } \\
\text { for the provision of state-of-the-art re- } \\
\text { porting }\end{array}$ & $\begin{array}{l}\text { Referral hospitals (location of spe- } \\
\text { cialist is not mentioned) }\end{array}$ \\
\hline $\begin{array}{l}\text { Wrenn et al } \\
\text { [29] }\end{array}$ & $\begin{array}{l}86 \text { Primary care providers } \\
(\mathrm{PCP}) \text { from eight adult pri- } \\
\text { mary care sites at the Uni- } \\
\text { versity of California, San } \\
\text { Francisco (UCSF), USA, } \\
195 \text { patients }\end{array}$ & $\begin{array}{l}\text { To analyse how the teleconsultation pro- } \\
\text { gram affects clinical management of pa- } \\
\text { tients in primary care }\end{array}$ & $\begin{array}{l}\text { Percentage of specialist recommendations } \\
\text { PCPs implemented, and the proportion of } \\
\text { patients with a specialist visit in the same } \\
\text { specialty as the teleconsultation, emergen- } \\
\text { cy department visit, or hospital admission } \\
\text { during the subsequent six months }\end{array}$ & $\begin{array}{l}\text { PCPs office (location of specialist } \\
\text { is not mentioned) }\end{array}$ \\
\hline
\end{tabular}


with multiple organ failure [36] and Weikert et al. included patients with presence of Usual Interstitial Pneumonia (UIP)-pattern in patients with suspected Idiopathic pulmonary fibrosis (IPF) [37].

\section{Study designs}

The 10 papers included in this review are summarised in Table 2 and the aims and outcome measures in the included studies are described in Table 4. There were no randomised controlled trials or controlled before-and-after studies. Four studies, which yielded five papers, were cross-sectional studies which described numbers of patients and health systems where teleconsultations were implemented $[28,31,32,34,36]$. Two of these five publications were about ongoing systems described retrospectively [28,34]. Three papers described the ongoing systems $[29,33,37]$, two of which used descriptive statistics to report the outcomes quantitatively $[29,37]$ and the remaining one was a narrative technical description of the teleconsultation system [33]. Only one study, which described three case reports, did not include any quantitative analysis [30] and one study described data at baseline and assessed the patients' clinical outcomes longitudinally after the intervention [35].

\section{Country of the studies}

All but one of the included studies were conducted in high-income countries. Five papers referred to four studies conducted in Europe [31-35], two in the US [28,29] and one each in Japan [30] and Iran [36]. One study was conducted in a network collaboration of 12 hospitals in Central Eastern Europe and Asia [37] (Table 2).

\section{Quality assessment and limitations of the included studies}

The quality assessment of the studies was done using JBI tools [27] (Table 5, Table 6 and Table 7). All papers were rated as moderate or low quality. Papers were assessed based on study types. Three papers were assessed as text or opinion papers (Table 5), half of the selected papers were analytical cross-sectional studies (Table 6), one a study of diagnostic accuracy and one a case study (Table 7) and were assessed using respective parameters. All the selected studies have certain limitations (Table 3 ). The opinion papers $[29,33,37]$ did not logically defend incongruence with the literature/sources, whereas the confounding factors were either not considered or mentioned in the cross-sectional analytical studies [28,31,32,34-36]. The one case study [30] reported is a low-quality paper.

Table 5. Quality assessment of the selected publications using the JBI tools for critical appraisal (text \& opinion papers)*

\begin{tabular}{|c|c|c|c|c|c|c|}
\hline STUDY TITLE & $\begin{array}{l}\text { 1. IS THE } \\
\text { SOURCE OF } \\
\text { THE OPINION } \\
\text { CLEARLY } \\
\text { IDENTIFIED? }\end{array}$ & $\begin{array}{l}\text { 2. DOES THE SOURCE } \\
\text { OF OPINION HAVE } \\
\text { STANDING IN THE } \\
\text { FIELD OF EXPERTISE? }\end{array}$ & $\begin{array}{l}\text { 3. ARE THE INTERESTS } \\
\text { OF THE RELEVANT } \\
\text { POPULATION THE } \\
\text { CENTRAL FOCUS OF } \\
\text { THE OPINION? }\end{array}$ & $\begin{array}{l}\text { 4. IS THE STATED } \\
\text { POSITION THE RESULT OF } \\
\text { AN ANALYTICAL PROCESS, } \\
\text { AND IS THERE LOGIC IN } \\
\text { THE OPINION EXPRESSED? }\end{array}$ & $\begin{array}{l}\text { 5. IS THERE } \\
\text { REFERENCE TO } \\
\text { THE EXTANT } \\
\text { LITERATURE? }\end{array}$ & $\begin{array}{l}\text { 6. IS ANY } \\
\text { INCONGRUENCE WITH } \\
\text { THE LITERATURE/ } \\
\text { SOURCES LOGICALLY } \\
\text { DEFENDED? }\end{array}$ \\
\hline Bernocchi et al [33] & 1 & 3 & 1 & 1 & 3 & 3 \\
\hline Weikert et al [37] & 1 & 1 & 1 & 1 & 2 & 2 \\
\hline Wrenn et al [29] & 1 & 3 & 1 & 1 & 1 & 3 \\
\hline
\end{tabular}

JBI - Joanna Briggs Institute

*1 = Yes, 2 =No, 3 =Unclear, 4 =not applicable.

Table 6. Quality assessment of the selected publications using the JBI tools for critical appraisal (analytical cross-sectional study)*

\begin{tabular}{|c|c|c|c|c|c|c|c|c|}
\hline \multirow{6}{*}{ STUDY TITLE } & 1. WERE THE & 2. WERE & 3. WAS THE & 4. WERE & 5. WERE & 6. WERE & 7. WERE THE & 8. WAS \\
\hline & CRITERIA FOR & THE STUDY & EXPOSURE & OBJECTIVE, & CONFOUNDING & STRATEGIES & OUTCOMES & APPROPRIATE \\
\hline & INCLUSION IN & SUBJECTS AND & MEASURED IN & STANDARD & FACTORS & TO DEAL WITH & MEASURED & STATISTICAL \\
\hline & THE SAMPLE & THE SETTING & A VALID AND & CRITERIA USED FOR & IDENTIFIED? & CONFOUNDING & IN A VALID & ANALYSIS \\
\hline & CLEARLY & DESCRIBED IN & RELIABLE WAY? & MEASUREMENT OF & & FACTORS & AND RELIABLE & USED? \\
\hline & DEFINED? & DETAIL? & & THE CONDITION? & & STATED? & WAY? & \\
\hline Raza et al [28] & 1 & 1 & 1 & 1 & 2 & 2 & 1 & 1 \\
\hline $\begin{array}{l}\text { Averame et al } \\
{[31]}\end{array}$ & 1 & 2 & 1 & 1 & 3 & 3 & 1 & 1 \\
\hline Bonavia et al [32] & 1 & 1 & 2 & 1 & 3 & 3 & 2 & 3 \\
\hline $\begin{array}{l}\text { Thijssing et al } \\
{[34]}\end{array}$ & 1 & 1 & 1 & 1 & 3 & 2 & 1 & 1 \\
\hline $\begin{array}{l}\text { Fadaizadeh et al } \\
\text { [36] }\end{array}$ & 1 & 1 & 1 & 1 & 2 & 2 & 1 & 1 \\
\hline Metting et al [35] & 1 & 1 & 3 & 1 & 2 & 2 & 3 & 1 \\
\hline
\end{tabular}

*1 = Yes, 2 =No, 3 =Unclear, 4 =not applicable. 
Table 7. Quality assessment of the selected publications using the JBI tools for critical appraisal (case report)*

\begin{tabular}{|c|c|c|c|c|c|c|c|c|}
\hline STUdY TITLE & $\begin{array}{l}\text { 1. WERE } \\
\text { PATIENT'S } \\
\text { DEMOGRAPHIC } \\
\text { CHARACTERISTICS } \\
\text { CLEARIY } \\
\text { DESCRIBED? }\end{array}$ & $\begin{array}{l}\text { 2. WAS THE } \\
\text { PATIENT'S } \\
\text { HISTORY CLEARLY } \\
\text { DESCRIBED AND } \\
\text { PRESENTED AS A } \\
\text { TIMELINE? }\end{array}$ & $\begin{array}{l}\text { 3. WAS THE CURRENT } \\
\text { CLINICAL CONDITION } \\
\text { OF THE PATIENT } \\
\text { ON PRESENTATION } \\
\text { CLEARLY DESCRIBED? }\end{array}$ & $\begin{array}{l}\text { 4. WERE } \\
\text { DIAGNOSTIC TESTS } \\
\text { OR ASSESSMENT } \\
\text { METHODS AND THE } \\
\text { RESULTS CLEARIY } \\
\text { DESCRIBED? }\end{array}$ & $\begin{array}{l}\text { 5. WAS THE } \\
\text { INTERVENTION(S) } \\
\text { OR TREATMENT } \\
\text { PROCEDURE(S) } \\
\text { CLEARLY } \\
\text { DESCRIBED? }\end{array}$ & $\begin{array}{l}\text { 6. WAS THE POST- } \\
\text { INTERVENTION } \\
\text { CLINICAL } \\
\text { CONDITION } \\
\text { CLEARLY } \\
\text { DESCRIBED? }\end{array}$ & $\begin{array}{l}\text { 7. WERE ADVERSE } \\
\text { EVENTS (HARMS) } \\
\text { OR UNANTICIPATED } \\
\text { EVENTS IDENTIFIED } \\
\text { AND DESCRIBED? }\end{array}$ & $\begin{array}{l}\text { 8. DOES THE } \\
\text { CASE REPORT } \\
\text { PROVIDE } \\
\text { TAKEAWAY } \\
\text { LESSONS? }\end{array}$ \\
\hline $\begin{array}{l}\text { Koizumi } \\
\text { et al [30] }\end{array}$ & 1 & 2 & 1 & 3 & 2 & 3 & 1 & 1 \\
\hline
\end{tabular}

*1 = Yes, 2 = No, 3 =Unclear, 4 = not applicable.

\section{CONCLUSIONS}

We found no controlled trials and relatively few papers mainly of a moderate or low quality which explored specialist to non-specialist teleconsultation in the management of CRDs. This is in contrast to other specialities where comparatively more papers are available describing doctor to nurse or specialist to non-specialist consultation including dermatology [38], psychiatry [39,40] and radiology [41].

Of the included papers a few described systems which did not focus on any one particular disease and lung diseases were just one of the conditions which were managed using these teleconsultation systems. Although some studies indicated that such specialist to non-specialist consultation may have resulted in more local treatment and a lower proportion of referred cases to specialists. The absence of baseline data in some means it is not clear to what extent it may have increased appropriate referrals for patients who previously did not have easy access to diagnosis.

Teleconsultation in the PCPs office with the remotely situated consultant in the hub and spoke model was the most preferred way of conducting specialists to non-specialist consultation and the audio mode was primarily used for consultation. This concludes to be one of the most logistically feasible models for PCPs and specialists and also fulfils the patients' requirements. Very few studies were conducted in the LMICs and most were reported from European counties. It is possible that specialist to non-specialist consultations for CRD diagnosis and management using teleconsultation are taking place but are not being reported in academic literature. The studies we selected were relatively recent and published during the last decade.

While the available literature does not indicate any generalizability, it shows some encouragement that specialist to non-specialist teleconsultation may facilitate diagnosis and management of CRDs to the benefit of patients. However, CRD diagnosis using specialist to non-specialist teleconsultation was more pragmatic and manageable as against the CRD management.

The use of teleconsultation may potentially help patients for CRD diagnosis and management, where face-toface consultations are not available [42]. Studies have proven to have a positive impact on the quality of life of the patients suffering from CRDs and acceptance by the health care provider [43]. Further, high-quality research to demonstrate the efficacy of the use of specialist to non-specialist consultation for managing CRDs is required to be conducted in controlled settings. A strategy to build evidence to deploy specialist to non-specialist teleconsultation to manage CRDs will aid further research $[44,45]$. More high-quality controlled studies are required to confirm these suggestions.

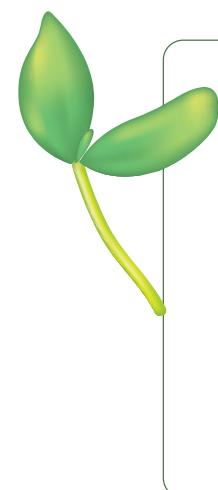

Acknowledgements: We are grateful to Marshall Dozier, Academic Librarian at the University of Edinburgh, for her help in developing the search strategy and guiding in data extraction and Dhiraj Agarwal for his critical review to the manuscript.

RESPIRE Collaborations: Prof. Hilary Pinnock (NIHR Global Health Research Unit on Respiratory Health (RESPIRE), Usher Institute, The University of Edinburgh), Prof. Harish Nair (NIHR Global Health Research Unit on Respiratory Health (RESPIRE), Usher Institute, The University of Edinburgh, Prof Aziz Sheikh (NIHR Global Health Research Unit on Respiratory Health (RESPIRE), Usher Institute, The University of Edinburgh), Prof Harry Campbell (NIHR Global Health Research Unit on Respiratory Health (RESPIRE), Usher Institute, The University of Edinburgh).

Disclaimer: The views expressed in the submitted article are those of the authors' own and not an official position of the institution or funder. 
Funding: RP is supported by PhD studentships from the NIHR Global Health Research Unit on Respiratory Health (RESPIRE). RESPIRE is funded by the National Institute of Health Research using Official Development Assistance (ODA) funding. This research was commissioned by the UK National Institute for Health Research (NIHR) Global Health Research Unit on Respiratory Health (RESPIRE), using UK Aid from the UK Government. The views expressed are those of the author(s) and not necessarily those of the NHS, the NIHR or the Department of Health and Social Care. Neither the funder nor the sponsor (University of Edinburgh) contributed to protocol development.

Authorship contributions: RP conceptualised the review with support from BM, KF and SJ. RP and RS conducted the search and data extraction and RP wrote the first draft of this manuscript. All authors gave critical comments and contributed to the manuscript.

Competing interests: The authors completed the ICMJE Unified Competing Interest form (available upon request from the corresponding author), and declare no conflicts of interest.

Additional material

Online Supplementary Document

1 World Health Organization. Density of physicians (total number per 1000 population, latest available year). 2019. Available: https://www.who.int/gho/health_workforce/physicians_density_text/en/. Accessed: 15 November 2020.

2 Bangdiwala SI, Fonn S, Okoye O, Tollman S. Workforce Resources for Health. Public Health Rev. 2010;32:296-318. doi:10.1007/BF03391604

3 Rao KD, Shahrawat R, Bhatnagar A. Composition and distribution of the health workforce in India: estimates based on data from the National Sample Survey. 2016;5(September).

4 Ministry of AYUSH Government of India. AYUSH in India. 2016.

5 European Coordination Committee of the Radiological Electromedical and Healthcare IT Industry. COCIR Telemedicine Toolkit of Teleheath and Mobile Health. 2011.

6 Mathur P, Srivastava S, Lalchandani A, Mehta JL. Evolving Role of Telemedicine in Health Care Delivery in India. Prim Health Care. 2017;7:1-6. doi:10.4172/2167-1079.1000260

7 Smith AC, Thomas E, Snoswell CL, Haydon H, Mehrotra A, Clemensen J, et al. Telehealth for global emergencies: Implications for coronavirus disease 2019 (COVID-19). J Telemed Telecare. 2020;26:309-13. Medline:32196391 doi:10.1177/1357633X20916567

8 World Health Organization. Global Diffusion of eHealth: Making UHC achievable. Geneva: WHO; 2016.

9 Rudel D, Fisk M, Roze R. Definitions of Terms in Telehealth. Infor Med Slov. 2011;16:28-46.

10 Banda HT, Thomson R, Mortimer K, Bello GAF, Mbera GB, Malmborg R, et al. Community prevalence of chronic respiratory symptoms in rural Malawi: Implications for policy. PLoS One. 2017;12:e0188437. Medline:29216193 doi:10.1371/journal. pone. 0188437

11 World Health Organization. Global Tuberculosis Report 2017. Geneva: WHO; 2017.

12 van Gemert F, van der Molen T, Jones R, Chavannes N. The impact of asthma and COPD in sub-Saharan Africa. Prim Care Respir J. 2011;20:240-8. Medline:21509418 doi:10.4104/pcrj.2011.00027

13 Ait-Khaled N, Enarson D, Bousquet J. Chronic respiratory diseases in developing countries: the burden and strategies for prevention and management. Bull World Health Organ. 2001;79:971-9. Medline:11693980

14 Global Asthma Network. The Global Asthma Report 2014. 2014. Available: http://www.globalasthmareport.org/2014/. Accessed: 10 October 2020.

15 Hilty M, Burke C, Pedro H, Cardenas P, Bush A, Bossley C, et al. Disordered microbial communities in asthmatic airways. PLoS One. 2010;5:e8578. Medline:20052417 doi:10.1371/journal.pone.0008578

16 Singh S, Singh N. Current trends of management of respiratory diseases by pulmonologists: Results of National Conference of Pulmonary Disease - 2015 survey. Lung India. 2017;34:13. Medline:28144054 doi:10.4103/0970-2113.197093

17 Croft JB, Lu H, Zhang X, Holt JB. Geographic Accessibility of Pulmonologists for Adults With COPD. Chest. 2016;150:54453. Medline:27221645 doi:10.1016/j.chest.2016.05.014

18 Indian Chest Society. List of Life members. 2018. Available: http://www.indianchestsociety.com/wp-content/uploads/2019/01/ State-wise-list-of-Life-ICS-Members-for-Website-updated-till-2493-and-dec-2018-Sheet1-1.pdf. Accessed: 20 August 2019.

19 American Thoracic Society. Membership. Available: https://www.thoracic.org/members/membership/. Accessed: 31 August 2020.

20 Koh D. NAING L. Health Workers: a global profile. In: The world health report. Geneva: WHO; 2006.

21 Cooke A, Smith DM, Cooke A, Smith D, Booth A. Beyond PICO: the SPIDER tool for qualitative evidence synthesis Beyond PICO: The SPIDER Tool for Qualitative Evidence Synthesis. Qual Health Res. 2012;22:1435-43. Medline:22829486 doi:10.1177/1049732312452938

22 The Mendeley Support Team. Getting Started with Mendeley. Mendeley Desktop. London: Mendeley Ltd.; 2011.

23 von Elm E, Altman DG, Egger M, Pocock SJ, Gøtzsche PC, Vandenbroucke JP. The strengthening the reporting of observational studies in epidemiology (STROBE) statement: Guidelines for reporting observational studies. Int J Surg. 2014;12:1495-9. Medline:25046131 doi:10.1016/j.ijsu.2014.07.013

24 The National Institute for Health and Care Excellence. Available: https://www.nice.org.uk/. Accessed: 3 November 2019. 
25 Critical Appraisal Skills Programme (CASP). Available: https://casp-uk.net/\#!casp-tools-checklists/c18f8. Accessed: 3 November 2019.

26 Consolidated Standards of Reporting Trials (CONSORT). Available: http://www.consort-statement.org/. Accessed: 3 November 2019.

27 Abend G. The Meaning of Theory. Available: https://www-jstor-org.ezproxy.is.ed.ac.uk/stable/pdf/20453103.pdf?refreqid=excelsior\%3A6d7c8be554ed71956d016e8c9d1cdb3d. Accessed: 15 January 2021.

28 Raza T, Joshi M, Schapira RM, Agha Z. Pulmonary telemedicine-A model to access the subspecialist services in underserved rural areas. Int J Med Inform. 2009;78:53-9. Internet. Medline:18809352 doi:10.1016/j.jimedinf.2008.07.010

29 Wrenn K, Catschegn S, Cruz M, Gleason N, Gonzales R. Analysis of an electronic consultation program at an academic medical centre: Primary care provider questions, specialist responses, and primary care provider actions. J Telemed Telecare. 2017;23:217-24. Medline:26940797 doi:10.1177/1357633X16633553

30 Koizumi T, Takizawa M, Nakai K, Yamamoto Y, Murase S, Fujii T, et al. Trial of Remote Telemedicine Support for Patients with Chronic Respiratory Failure at Home through a Multistation Communication System. Telemed J E Health. 2005;11:4816. Medline:16149895 doi:10.1089/tmj.2005.11.481

31 Averame G, Bonavia M, Ferri P, Moretti AM, Fogliani V, Cricelli C, et al. Office spirometry can improve the diagnosis of obstructive airway disease in primary care setting. Respir Med. 2009;103:866-72. Medline:19200705 doi:10.1016/j.rmed.2008.12.017

32 Bonavia M, Averame G, Canonica W, Cricelli C, Fogliani V, Grassi C, et al. Feasibility and validation of telespirometry in general practice: The Italian "Alliance" study. Respir Med. 2009;103:1732-7. Medline:19497726 doi:10.1016/j.rmed.2009.05.006

33 Bernocchi P, Scalvini S, Tridico C, Borghi G, Zanaboni P, Masella C, et al. Healthcare continuity from hospital to territory in Lombardy: TELEMACO project. Am J Manag Care. 2012;18:e101-8. Medline:22435961

34 Thijssing L, van der Heijden JP, Chavannes NH, Melissant CF, Jaspers MWMM, Witkamp L. Telepulmonology: Effect on quality and efficiency of care. Respir Med. 2014;108:314-8. Medline:24210893 doi:10.1016/j.rmed.2013.10.017

35 Metting EI, Riemersma RA, Kocks JH, Piersma-Wichers MG, Sanderman R, van der Molen T. Feasibility and effectiveness of an asthma/COPD service for primary care: a cross-sectional baseline description and longitudinal results. NPJ Prim Care Respir Med. 2015;25:14101. Medline:25569634 doi:10.1038/npjpcrm.2014.101

36 Fadaizadeh L, Shajareh E, Taheri MJ, Heydari G, Fazanegan B, Sistani M. Role of Telemedicine in Pace of Consultation and Physicians' Satisfaction in Thoracic Surgery ICU. Tanaffos. 2018;17:117-21. Medline:30627183

37 Weikert T, Sommer G, Tamm M, Haegler P, Cyriac J, Sauter AW, et al. Centralized expert HRCT Reading in suspected idiopathic pulmonary fibrosis: Experience from an Eurasian teleradiology program. Eur J Radiol. 2019;121:108719. Medline:31706232 doi:10.1016/j.ejrad.2019.108719

38 van der Heijden JP, Spuls PI, Voorbraak FP, de Keizer NF, Witkamp L, Bos JD. Tertiary Teledermatology: A Systematic Review. Telemed J E Health. 2010;16:56-62. Medline:20064068 doi:10.1089/tmj.2009.0020

39 Fortney JC, Pyne JM, Turner EE, Farris KM, Normoyle TM, Avery MD, et al. Telepsychiatry integration of mental health services into rural primary care settings. Int Rev Psychiatry. 2015;27:525-39. Medline:26634618 doi:10.3109/09540261.2015.1085838

40 Sheahan B. Remote communities, child telepsychiatry and primary health care. Youth Stud Aust. 2002;21:52-5.

41 Dang S, Gomez-Orozco CA, van Zuilen MH, Levis S. Providing Dementia Consultations to Veterans Using Clinical Video Telehealth: Results from a Clinical Demonstration Project. Telemed J E Health. 2018;24:203-9. Medline:28686082 doi:10.1089/ tmj.2017.0089

42 Zhang J, Stahl JN, Huang HK, Member S, Zhou X, Lou SL, et al. Real-Time Teleconsultation with High-Resolution and Large-Volume Medical Images for Collaborative Healthcare. 2000;4:178-85.

43 Pinnock H, Mckinstry B. Telehealth for COPD: promises, populations and personalised care. AJRCCM. 2018;1-8.

44 McLean S, Nurmatov U, Liu JL, Pagliari C, Car J, Sheikh A. Telehealthcare for chronic obstructive pulmonary disease. Cochrane Database Syst Rev. 2011;CD007718. Medline:21735417

45 McKinstry B, Pinnock H, Sheikh A. Telemedicine for management of patients with COPD? Lancet. 2009;374:672-3. Medline:19716948 doi:10.1016/S0140-6736(09)61542-7 